\title{
Review
}

Journal of Innate

Immunity
J Innate Immun 2013;5:197-208

DOI: $10.1159 / 000346374$
Received: November 2, 2012

Accepted after revision: December 6, 2012

Published online: February 5, 2013

\section{Pulmonary Surfactant Protein D in First-Line Innate Defence against Influenza A Virus Infections}

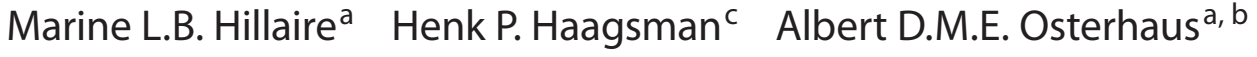 \\ Guus F. Rimmelzwaan ${ }^{\mathrm{a}, \mathrm{b}}$ Martin van Eijk ${ }^{\mathrm{c}}$ \\ ${ }^{a}$ Erasmus Medical Centre, Department of Viroscience, and ${ }^{b}$ Viroclinics Biosciences BV, Rotterdam, and \\ 'Department of Infectious Diseases and Immunology, Faculty of Veterinary Medicine, Utrecht University, \\ Utrecht, The Netherlands
}

\section{Key Words}

Influenza A virus · Collectins · Innate immunity · Viral glycosylation · Pulmonary defense · Antiviral drugs · C-type lectins $\cdot$ Sialic acids $\cdot$ Lung inflammation

\begin{abstract}
Influenza A viruses (IAV) cause respiratory tract infections annually associated with excess mortality and morbidity. Nonspecific, innate immune mechanisms play a key role in protection against viral invasion at early stages of infection. A soluble protein present in mucosal secretions of the lung, surfactant protein D (SP-D), is an important component of this initial barrier that helps to prevent and limit IAV infections of the respiratory epithelium. This collagenous C-type lectin binds IAVs and thereby inhibits attachment and entry of the virus but also contributes to enhanced clearance of SP-D-opsonized virus via interactions with phagocytic cells. In addition, SP-D modulates the inflammatory response and helps to maintain a balance between effective neutralization/killing of IAV, and protection against alveolar damage resulting from IAV-induced excessive inflammatory responses. The mechanisms of interaction between SP-D and IAV not only depend on the structure and binding properties of SP-D
\end{abstract}

but also on strain-specific features of IAV, and both issues will be discussed. SP-D from pigs exhibits distinct anti-IAV properties and is discussed in more detail. Finally, the potential of SP-D as a prophylactic and/or therapeutic antiviral agent to protect humans against infections by IAV is discussed.

Copyright $\odot 2013$ S. Karger AG, Basel

\section{Introduction}

Collectins, First-Line Defense Proteins of the Innate Immune System

The innate immune system plays an essential role in host defense since it is the initial barrier that provides protection against invading pathogens. It includes physical barriers such as the skin, the mucosal epithelia of the lungs and the gastrointestinal and reproductive tract, different cells such as macrophages, neutrophils or natural killer cells and soluble molecules such as the components of the complement system, pattern recognition receptors and cytokines. Upon microbial challenge, the innate immune system generates an acute-phase-like response, characterized by limited specificity and lack of memory,

\section{KARGER \\ Fax +4161306 1234 \\ E-Mail karger@karger.ch}

www.karger.com (c) 2013 S. Karger AG, Base

$1662-811 X / 13 / 0053-0197 \$ 38.00 / 0$

Accessible online at:

www.karger.com/jin
Dr. Martin van Eijk

Department of Infectious Diseases and Immunology, Faculty of Veterinary Medicine Utrecht University, Yalelaan 1

NL-3584 CL Utrecht (The Netherlands)

E-Mail m.vaneijk@uu.nl 
in contrast to the adaptive immune response. The recognition of nonself antigen is key in the induction of the innate immune response. Such nonself antigens include pathogen-associated molecular patterns known as PAMPs, which are conserved molecular signatures of pathogens such as lipopolysaccharide, double- or singlestranded RNA, mannose-rich glycans or peptidoglycans. PAMPs are highly conserved molecular structures that play a key role in the survival and/or virulence of pathogens [1]. Several cells and molecules of the innate immune system can recognize PAMPs, including a group of innate immune proteins known as 'collectins' which are involved in early stages of host defense against a broad range of microorganisms that include Gram-positive and Gram-negative bacteria, viruses, fungi and yeasts.

The collectin family includes different members and although they are considered evolutionary ancient, their occurrence and structural/functional characteristics show (subtle) variations even amongst mammalian species. In humans, the three major members of this protein family comprise surfactant protein A (SP-A), surfactant protein D (SP-D) and mannose-binding lectin. SP-A and SP-D are constitutively secreted into the lungs by alveolar type II cells and unciliated bronchial epithelial cells [2], but they can also be produced in other mucosal tissues [3-5]. In contrast, mannose-binding lectin is a serum collectin that is produced in the liver and plays an important role in complement activation via the lectin pathway. The polypeptide structure of all collectins is characterized by the presence of a cysteine-rich $\mathrm{N}$-terminal domain, a collagenous domain, a trimerizing neck domain and a Ctype lectin domain (carbohydrate recognition domain, CRD) which adopts a stable carbohydrate-binding conformation in the presence of $\mathrm{Ca}^{2+}$ (fig. 1a). All collectins known to date assemble into trimers and in most cases these subunits arrange into higher-order oligomers (fig. 1b) that are able to recognize and bind to patterns of glycoconjugates expressed on the surface of pathogens. As a result of this interaction, collectins participate in neutralization and clearance of a wide range of microorganisms including bacteria, fungi and viruses [6]. This review focuses on the role of the 'pulmonary collectin' SP-D in early defense against the respiratory pathogen influenza A virus (IAV). The following paragraph summarizes several important characteristics of IAV.

\section{Characteristics of IAV}

IAV is a major cause of respiratory tract infections resulting in a highly contagious disease that leads to excess morbidity and mortality every year [7]. Different sub-

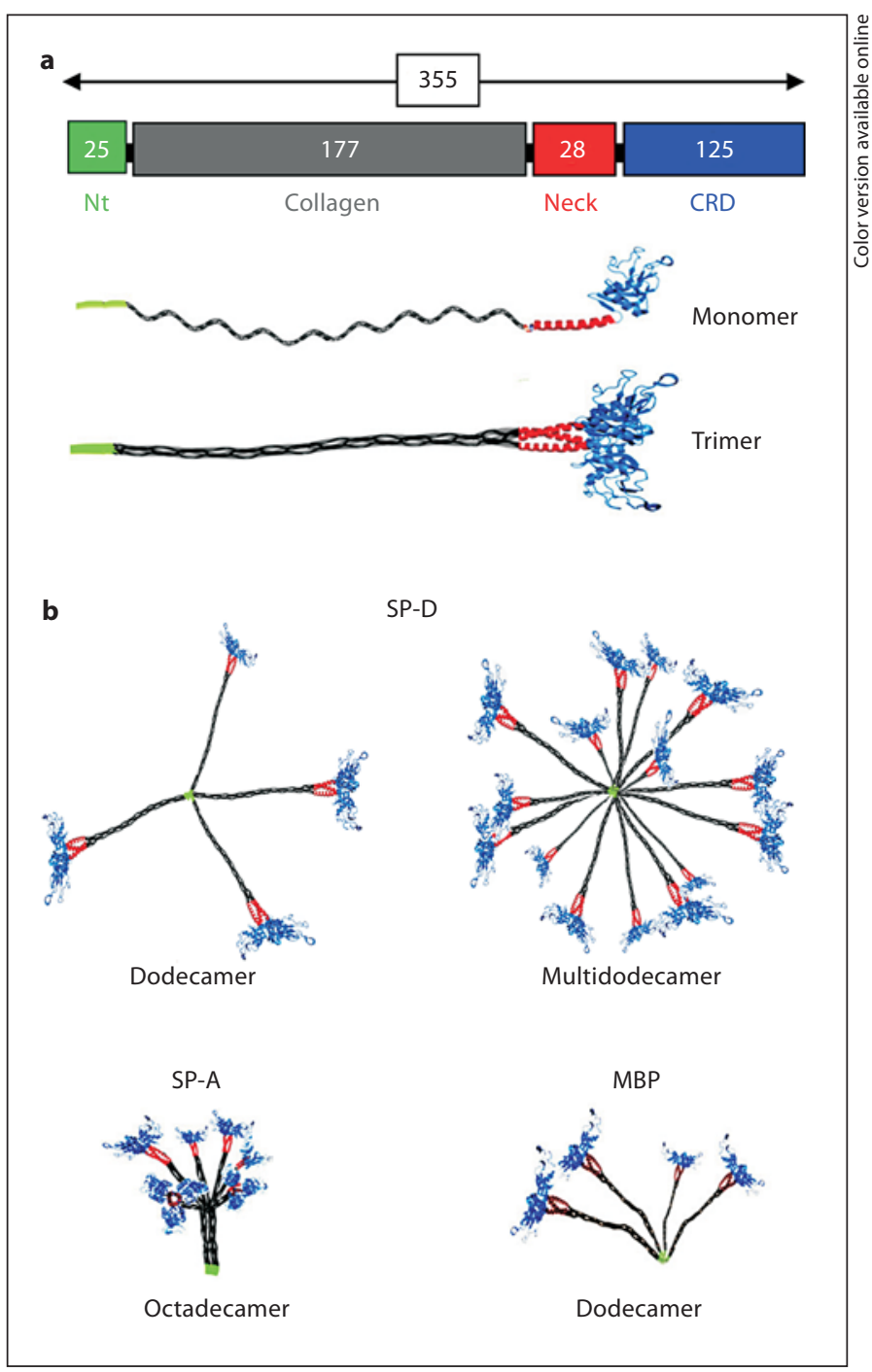

Fig. 1. Molecular structure of collectins. a Schematic domain organization of the polypeptide chains of all collectins, consisting of a cysteine-rich $\mathrm{N}$-terminal domain $(\mathrm{Nt})$, a collagen-like region (Collagen), a short region that initiates trimerization by forming a short alpha-helical coiled-coil between three polypeptide chains (Neck), and a C-type lectin domain also referred to as CRD that recognizes glycan structures in a $\mathrm{Ca}^{2+}$-dependent manner. The number of amino acids that comprises a mature SP-D polypeptide and its distinct domains are indicated. Structural variations within the polypeptide chain exist between different members of the collectin family but may also result from animal-species-specific differences within one class. The most important ones include: number and location of cysteine residues, variable length of the collagen domain, differences in $\mathrm{N}$ - and $\mathrm{O}$-linked glycosylation profiles, and variability of residues flanking the ligand-binding pocket [82]. A general feature of all collectins is their ability to form trimers, resulting in well-defined spatial arrangements of three CRDs, which is important for glycan pattern-mediated recognition of nonself structures (e.g. pathogens). b Trimeric subunits can be further assembled into higher-order oligomers as illustrated for the three well-characterized collectins in humans: SP-D, SP-A and MBP. 


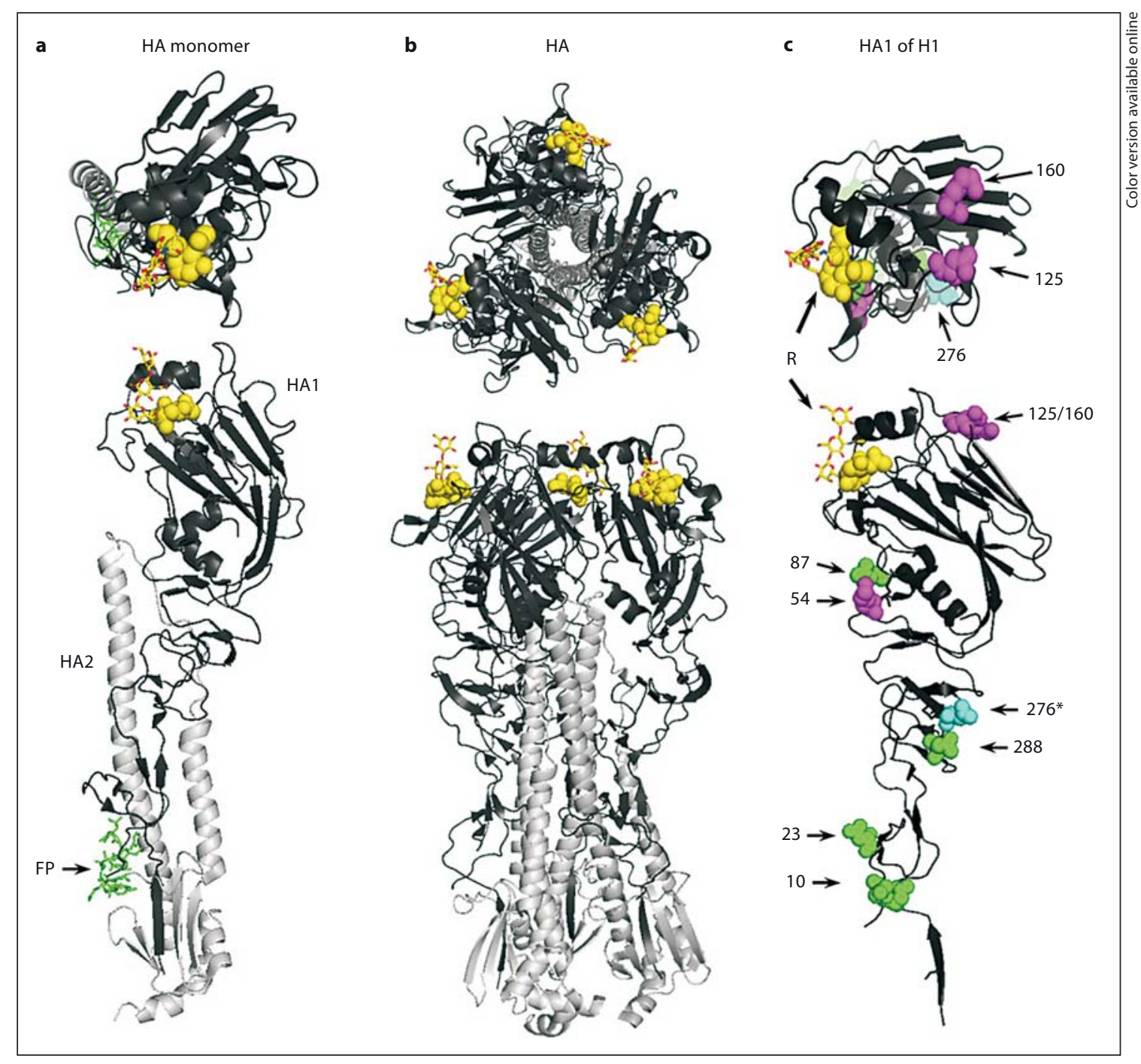

Fig. 2. Structure of the IAV surface protein HA. a Ribbon diagram of the HA monomer, consisting of the HA1 subunit (globular domain, black ribbon) and the HA2 stalk region (grey ribbon) which contains the fusion peptide (sticks, FP). Location of the SA receptor is indicated by a bound $\alpha(2,6)$-linked SA moiety (spheres) attached to Gal $\beta 1-4 \mathrm{GlcNac}$ (sticks). b Molecular organization of a mature HA trimer. Three HA monomers with HA1 and HA2 domains and SA receptors visualized as in a assembled into a single mature HA molecule as present in the viral envelope. c Detailed view of a single globular domain (HA1) derived from the 2009 pandemic H1 structure. Spheres indicate the locations of potential N-glycosylation sites as generally found in H1-sub-

types of IAV are defined depending on their two surface proteins, the hemagglutinin (HA) and the neuraminidase (NA). A total of 17 types of HA and 9 types of NA are reported and in theory any combination is possible. HA is the predominant protein in the viral envelope and plays type strains of IAV. Shown are the predicted glycosylation patterns with numbers indicating the asparagine residues within the HA protein sequence that correspond with these glycosylation sites. These are shown for A/NL/26/07 (representing a recent seasonal H1 strain: No. 54, 125 and 160) and for A/NL/602/09 (representing the pandemic $2009 \mathrm{H} 1 \mathrm{~N} 1$ strain) either only present in the pandemic 2009 H1N1 strain (No. 276, highlighted with an asterisk) or shared with seasonal $\mathrm{H} 1$ (all others). The SA receptor is shown as described in $\mathbf{a}$ and indicated with $\mathrm{R}$. In all panels top view is given at the top and side view at the bottom (adapted from the H1 structure of A/California/04/2009, PDB accession No. 3UBE [83]).

an important role in the virus cycle since it is the IAV receptor binding protein that recognizes sialic acid (SA; fig. 2a) [8-10]. This receptor-mediated interaction results in attachment, entry and fusion of the viral envelope with the endosomal membrane. By distinguishing between 
specific SA linkages, the receptor specificity dictates viral tropism and host specificity. The HA of human IAVs recognizes a (2,6)-linked sialosaccharides (NeuAca2-6Gal) that are mainly present in the upper respiratory tract of humans [11-13], whereas the HA of avian IAV recognizes $\alpha(2,3)$-linked sialosaccharides (NeuAca2-3Gal) that are found in the avian gastrointestinal tract and in the lower region of the human respiratory tract [14-16]. After the fusion event, the RNA segments are released in the cytosol and delivered into the nucleus where replication and transcription of the viral RNA take place. New viral particles are assembled at the membrane and budding is facilitated by the viral NA that enzymatically cleaves off SA residues from the infected cell, resulting in release of the virus from the infected host cells.

Most commonly inactivated influenza vaccines are used to protect individuals from contracting influenza and these vaccines mainly aim at the induction of antibodies against IAV membrane glycoproteins in particular HA. However, due to their high mutation rate, IAV evolve rapidly and undergo antigenic changes that are known as antigenic drift [17]. As a consequence, vaccines have to be adapted annually to match the circulating seasonal IAV. Moreover, novel antigenically distinct IAV can be introduced into the human population (antigenic shift), which may give rise to pandemic outbreaks and numerous deaths before a sufficient number of vaccine doses can be produced and distributed, as was the case during the 2009 pandemic [18]. Considering these limitations, it is important to develop alternative antiviral strategies that may help to protect the human population against infections with novel IAV. SP-D, a natural component of our innate immune system, is able to recognize and neutralize a wide range of subtypes of IAV and could be a venue for development of a novel, broad-spectrum antiviral drug against IAV.

\section{SP-D-Mediated Inhibition of IAV in vitro}

\section{Multivalency of Interactions between SP-D and IAV}

SP-D polypeptides assemble into trimers and these trimeric subunits can be further oligomerized into higherorder multimers like dodecamers, stabilized by disulfide bonds present in the $\mathrm{N}$-terminal region (fig. 1b) [19]. The trimeric configuration of each subunit facilitates multivalent high-avidity interactions between three clustered CRDs at the C-terminus of a single collectin arm, with specific patterns of glycoconjugates as present on the surface of IAV. The dimensions and spatial organization of three clustered SP-Ds match those of the trimeric HAs on IAV (fig. 2b) and this results in strong binding of viral glycans as present on the HA of IAV. Although there are reports indicating that SP-D also binds glycans present on NA [20], this interaction is considered less important given the 5-fold higher abundance of HA on the viral surface and the more extended configuration of the HA molecule. Of note, several studies showed that SP-D is able to inhibit NA activity either indirectly by binding adjacent HA molecules causing steric hindrance and blocking access of NA substrates (studies with intact virus [21]), or directly by binding NA resulting in reduction of NA activity [22].

Aggregation of IAV is an important neutralization mechanism that helps to prevent viral particles from infecting pulmonary epithelial cells. In addition, viral aggregate formation allows phagocytic cells to enhance neutralization and clearance of IAV more efficiently [23]. Viral aggregation requires multitrimeric structures like dodecameric SP-D. Several IAV neutralization studies with SP-D preparations expressed and purified in different degrees of assembly have underlined this correlation between the state of oligomerization and the IAV neutralization activity [24-26]. These results are of special interest since in humans there is a common polymorphism at position 11 (Met/Thr) of the mature protein sequence and the SP-D Thr/Thr11 form assembles predominantly as trimers that also have reduced antiviral capacity. Therefore, the presence of this polymorphism in humans may correlate with an enhanced susceptibility to IAV infections [24].

\section{SP-D Binds IAV via Its CRD}

The first in vitro studies showing that SP-D inhibits IAV were performed by Hartshorn et al. [27]. By using native rat SP-D and recombinant forms of rat and human SP-D they could demonstrate SP-D-mediated inhibition of H3N2 and H1N1 subtypes of IAV. This inhibitory activity proofed to be $\mathrm{Ca}^{2+}$-dependent, indicating that the CRD of SP-D is involved in interactions with glycans present on the surface of IAV (fig. 3a). Several in vitro studies were published illustrating the comparatively strong inhibitory activity of SP-D against IAV and of the human collectins, SP-D is in general the most potent in neutralizing IAV as compared to SP-A and mannosebinding lectin [27-29].

Recognition of IAV by SP-D is mediated via its CRD. Like all collectins (except CL-P1), SP-D is a mannosetype lectin, preferentially binding mannose-type glycans over galactose-type glycans [30]. However, the carbohy- 
Fig. 3. Model of the molecular interactions between SP-D and HA. a The protein structure of the HA trimer (see fig. 2 for strain details) depicted as black ribbon diagrams and the location of the SA receptor indicated with a bound SA molecule (bright spheres). The presence (top) or absence (bottom) of N-linked glycosylations at sites N125 and N160 is schematically represented as larger clusters of spheres. The ribbon diagram on the right shows the structure of the neck-CRD fragment of hSP-D (PDB accession No. 3G83 [32]) with the sugar binding site indicated by a complexed mannose ligand (sticks). Interactions between hSP-D and IAV are limited to those strains that bear N-glycans on their HA molecules (calcium-dependent CRD-mediated interactions, lectin arrows). b As a but hSP-D replaced by pSP-D which has an SA-rich $\mathrm{N}$-linked glycan present in its CRD, schematically represented by clusters of spheres. This provides a second mode of interaction with the SA receptor of IAV (SA arrows) that results in an overall stronger binding between pSP-D and glycosylated IAVs (top) and allows binding to poorly glycosylated IAV strains (bottom); this is in contrast to hSP-D. c Top view and size comparison of a trimeric pSP-D neckCRD fragment and a glycosylated HA trimer (top view).

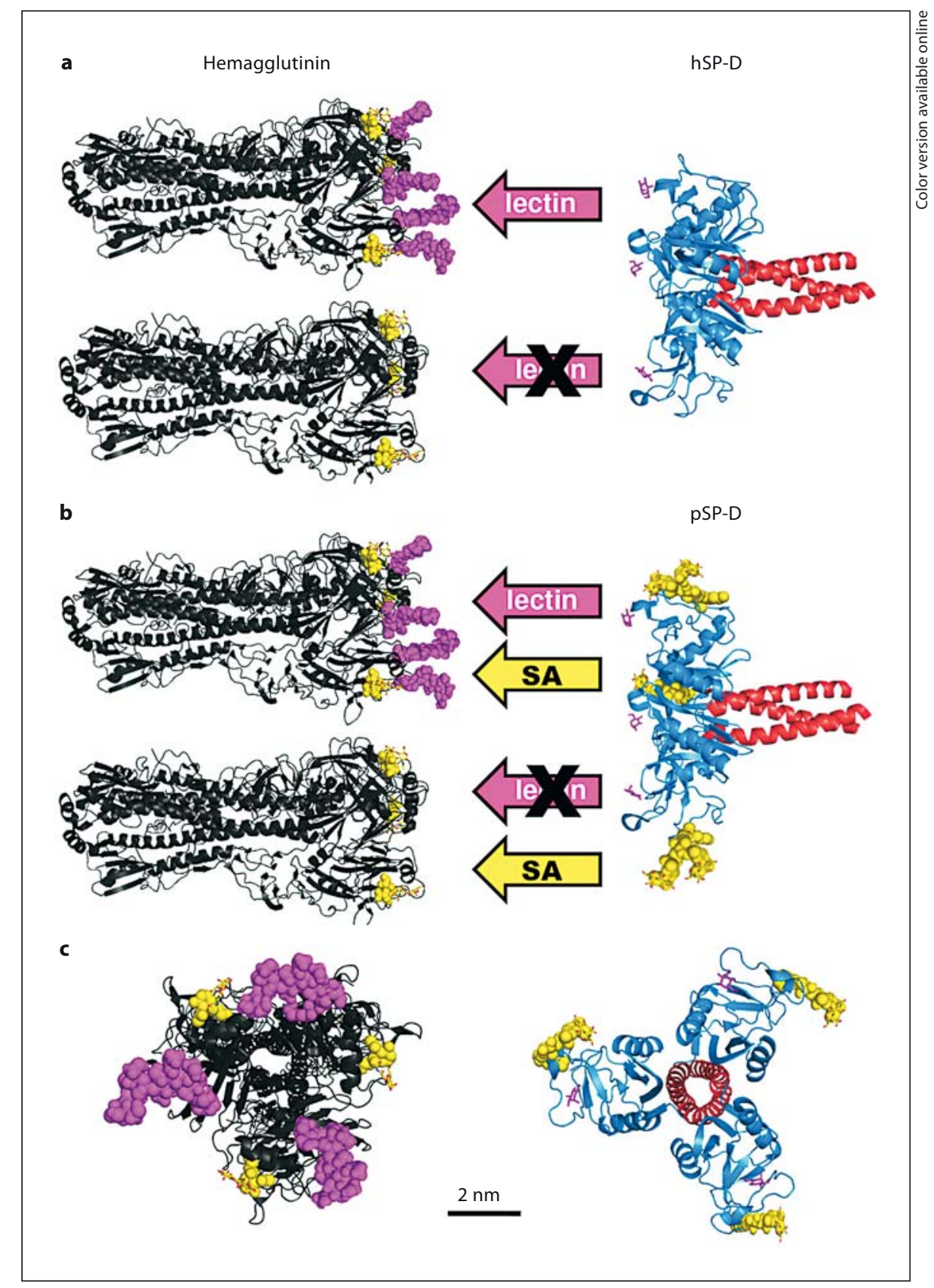

drate binding specificity of SP-D shows subtle animal species-specific variations and this is determined by differences in specific residues located in the sugar binding pocket of the CRD [31, 32]. While human SP-D (hSP-D) has a high affinity for $\mathrm{N}$-acetyl-mannosamine, rat and mouse SP-D preferentially recognize myo-inositol, maltose and glucose [31] and porcine SP-D (pSP-D) prefers mannose, maltose and glucose $[33,34]$. Apart from the glycan species, the number of glycans present on HA (and to a lesser extent on NA) and their exact location on the IAV surface proteins are also important factors in mediating recognition by SP-D. Several investigations have indicated that the number of Asn-linked glycosylations on HA affects the susceptibility of IAV to inhibition by SP-D and that the degree of HA glycosylation correlates with virulence of IAV in mice. This will be described in more detail in the section below. 


\section{HA Glycosylation versus Neutralization of IAV by $S P-D$}

Glycosylation of IAV is not only important for structural stability and integrity of HA and NA, but it also provides an effective means of immune evasion by shielding antigenic sites on the viral HA [35]. As a result of antigenic drift, human strains tend to accumulate glycosylation sites and in vivo experiments showed that mice are less susceptible to infection with more recent human IAV strains [36]. The accumulation of glycans on HA might be driven by antibody pressure since glycosylation may result in masking of neutralization epitopes present on $\mathrm{HA}$ and subsequent evasion from antibody-mediated neutralization by the host [37]. This inverse correlation between the extent of glycosylation of a particular IAV strain and its virulence in naïve mice precludes involvement of preexisting adaptive immunity and was attributed to increased IAV susceptibility to SP-D-mediated inhibition, as well as recognition and killing of virus that involves the mannose receptor on macrophages [36, 3841]. Of interest, the HA proteins of pandemic viruses (1918, 1957, 1968 and 2009) are poorly glycosylated and these caused alveolitis and bronchiolitis, in contrast to a seasonal H1N1 strain that induced only mild disease in infected mice [42]. The low number of N-linked glycans on these viruses correlates with a low susceptibility to SPD-mediated neutralization $[42,43]$. In contrast, seasonal viruses that are sensitive to SP-D cause relatively mild disease [42]. It can be hypothesized that infection with a SP$\mathrm{D}$-insensitive IAV strain results in higher virus replication and more clinical signs while infection with a SP-Dsensitive strain leads to a milder clinical course as SP-D can neutralize the virus and may help to reduce the spread of virus (fig. 4). However more studies are needed to determine the correlation between sensitivity to SP-D, glycosylation and pathogenicity of IAV.

In recent studies, reverse genetics on IAV was applied to study the impact of introducing or deleting N-glycosylation sites in the viral HA for IAV susceptibility to SP$\mathrm{D}$-mediated neutralization. The number of glycosylation sites that was introduced in the HA of IAV A/Hong Kong/1/68 (H3N2) determined the sensitivity of the virus to hSP-D [44] and was shown to be inversely correlated with viral virulence. These findings were confirmed using another $\mathrm{H} 3 \mathrm{~N} 2$ virus showing that presence of $\mathrm{N}$-linked glycans at positions N165 and N246 contributed to attenuation of the virus and increased susceptibility to SP-D [40] and that the loss of a single glycosylation site at N246 was associated with resistance to SP-D but also to higher virulence in mice [39]. Previously it was also shown in studies with the reassortant H3N2 strain X79 that deletion of the glycosylation site at position N165 of the HA of IAV resulted in decreased sensitivity to SP-D inhibition [45]. Furthermore, it was shown that the Nlinked glycosylation site at position N165 in H3N2 virus is absent in a collectin-resistant strain [46]. The importance of N165 as an important target for SP-D to interact with $\mathrm{H} 3$ subtypes is underlined by a study that described the predicted glycosylation profiles of various IAV HA subtypes. Analysis of 2,800 H3N2 full-length sequences (from all hosts and geographic regions) revealed that in general $\mathrm{H} 3$ s have up to 6 glycosylation sites in their globular domain of which N165 appears to be the most conserved glycosylation site in $\mathrm{H} 3$ sequences [47]. This may at least in part explain why IAV strains of the $\mathrm{H} 3$ subtype are in general much more susceptible to SP-D-mediated neutralization as compared to IAV strains from other HA subtypes.

The correlation between glycan attachment sites on the HA and susceptibility to neutralization by SP-D was also demonstrated for several IAV strains of the H1N1 subtype. Based upon $\mathrm{H} 1$ sequence numbering of the mature protein, glycosylation of the head region of $\mathrm{H} 1$ tends to be clustered in 2 distinct regions: around the base of the head region (centered around N54 and N87) or in the globular head region (centered around 125 and 160 [47]; fig. 2c). Interestingly, the $\mathrm{N}$-glycan at $\mathrm{N} 87$ has been present in all strains since 1977 and was shown to be important for inhibition by SP-D [46]. This glycan was predicted to be absent in the pandemic 1918 strain that also lacked glycosylation in the globular head region [48]. SP-D sensitivity tests using a panel of different $\mathrm{H} 1 \mathrm{~N} 1$ isolates revealed that glycans at N125 and N155 are important for inhibition by SP-D and this was underlined by virulence studies in mice [41]. By using PR-8 as a model strain for the introduction of N-glycosylation sites it was shown that especially N125 appears important for neutralization by SP-D [43], probably due to the location of N125 being in close proximity of the SA receptor. Recently, our group performed a reverse genetics study in which the pandemic $2009 \mathrm{H} 1 \mathrm{~N} 1$ strain and a seasonal 2007 H1N1 strain were used to investigate the relative importance of the number and the position(s) of N-glycosylation sites in the head region of the HA for susceptibility of these IAV strains to the neutralizing activity of pSP-D [49]. It was shown that in contrast to the seasonal H1N1 strain, pandemic $2009 \mathrm{H} 1 \mathrm{~N} 1$ lacks the 2 important Nlinked glycans at N125 and N160 in its globular head region, making this strain highly resistant against pSP-D; by introducing these $2 \mathrm{~N}$-glycans into the pandemic 2009 


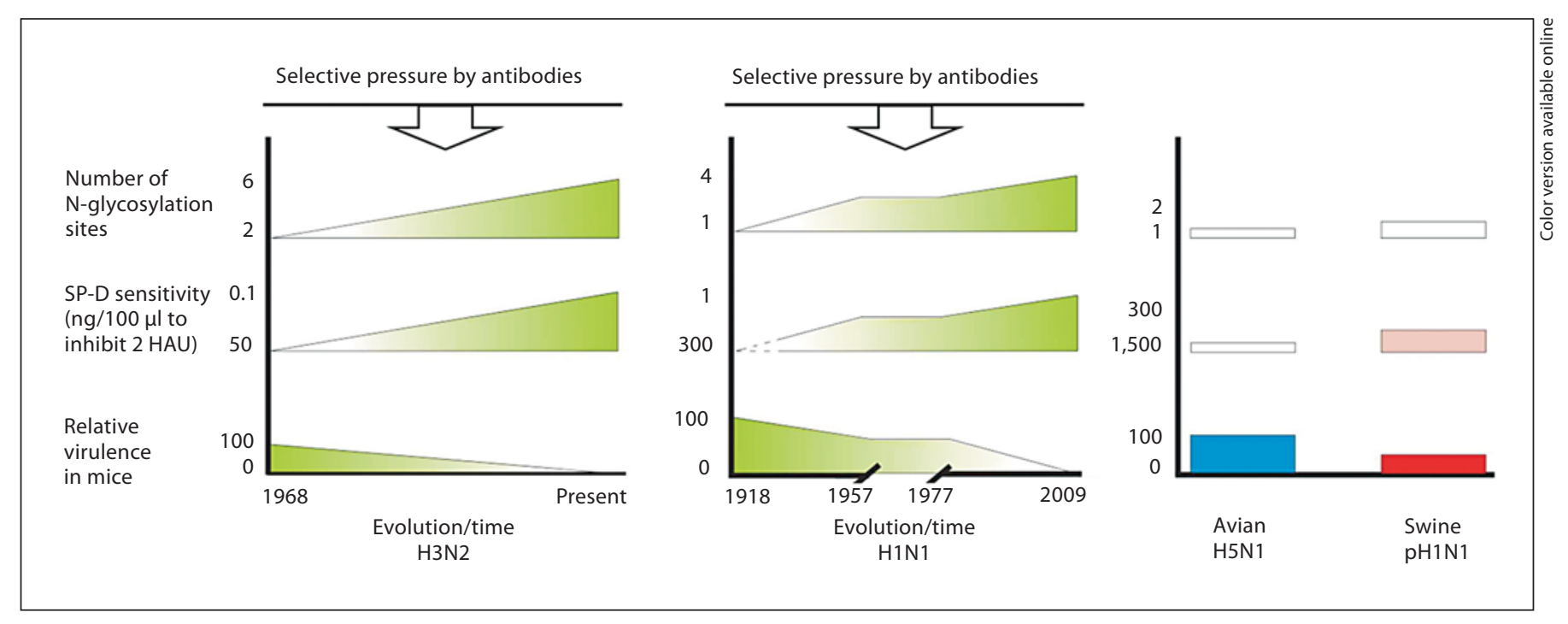

Fig. 4. Hypothetical correlation between the number of N-glycosylation sites, sensitivity to SP-D, and relative virulence. It is hypothesized that a higher degree of HA-glycosylation results in higher susceptibility to SP-D-mediated neutralization that leads to a reduced degree of virulence displayed by these IAV strains. A lower number of glycosylations correlates with higher virulence. These correlations are shown for seasonal IAVs [highlighted in green: H3N2 subtype (left panel) and H1N1 subtype (middle pan-

strain this resistance was counterbalanced. The reverse effect was observed using the seasonal H1N1 strain (susceptible to SP-D) and deleting the N125 glycan, resulting in a mutant that is much more resistant to SP-D. Interestingly, this same study showed that deletion of N276, present at the base of the head region of HA from pandemic H1N1 but absent in seasonal H1N1, substantially enhanced resistance against pSP-D. Taken together, these findings illustrate the importance of the degree of HA glycosylation and which positions/regions of the HA appear relatively important to facilitate glycan-dependent interactions between HA and SP-D resulting in more efficient clearance of IAV. IAV strains that circulate in low-mutation-pressure hosts like pigs and birds generally share poorly glycosylated globular domains of their HAs and when successfully introduced into the human population, may develop into pandemics (2009 H1N1, 1918 H1N1 [50]) or display pandemic potential as in the case of glycan-deficient H5N1 strains [51]. It remains to be investigated how resistance of these IAVs to early innate immune defense components, such as SP-D, contribute to their virulence and clinical severity that in most cases follows after infection with these strains. Figure 4 illustrates a hypothetical comparison between the degree of el)] and for avian H5N1 (blue) and pandemic H1N1 (red) (right panel). Indicated are the number of N-glycosylation sites in the head region of HA, sensitivity to SP-D, and relative virulence (on a scale from 0 to 100). For longer circulating IAV subtypes (H3N2 and $\mathrm{H} 1 \mathrm{~N} 1$ ) evolution of these viral characteristics is displayed on the $\mathrm{x}$-axis as a function of time (years) (color only in online version). HAU = HA units.

viral glycosylation, SP-D sensitivity, tissue tropism and relative virulence, restricted for those subtypes that are known to infect the human population.

\section{Immunomodulatory Roles of SP-D}

Binding of IAV by SP-D contributes to immediate protection against infection due to aggregation of viral particles, resulting in a reduction of the number of infectious particles in the lungs. However, the formation of SP-D/IAV complexes can also result in distinct interactions with immune cells leading to enhanced phagocytosis and modulation of the inflammatory response. Extensive studies on the interactions between neutrophils and SP-D have shown that SP-D is chemotactic for neutrophils $[52,53]$ and can bind SIRPa and SIRP $\beta$ [54], two surface proteins on neutrophils involved in neutrophil migration, phagocytosis and cytokine secretion. After IAV infection of the respiratory tract, neutrophils infiltrate the site of infection and are activated. IAV can cause neutrophil dysfunction and induce apoptosis, which may predispose to secondary bacterial infections. IAVs are also responsible for the deactivation of the neutrophils by 
inhibiting the respiratory burst (rapid release of reactive oxygen species by phagocytic cells to degrade internalized pathogens). This phenomenon is mediated via HA which is able to cross-link sialylated surface receptors of the cell. Multimers of RhSP-D enhance binding of IAV to neutrophils in vitro. This is thought to be mediated via SP-Dinduced aggregation of the virus, which would promote the binding of these large aggregates to neutrophils and would help the clearance by phagocytic mechanisms [27, 55]. Multimeric forms of SP-D also enhance neutrophil activation and protect the neutrophils against deactivation caused by IAV $[55,56]$ in contrast to trimeric forms of RhSP-D which inhibit IAV less efficiently, do not cause viral aggregation and are unable to protect neutrophils against deactivation [23]. Interactions of SP-D with neutrophils can be influenced by external factors. During acute infection, neutrophils and SP-D collaborate to clear IAV. However, if there is a chronic neutrophil activation preceding IAV infection, this will interfere with SP-Dmediated protection of neutrophils against IAV infection [57]. Furthermore, human neutrophil defensins interfere with the antiviral properties of SP-D [58].

SP-D can also interact with TLR2 and TLR4 $[59,60]$. It is known that TLR4 mediates lung injury during H5N1 infection [61] and other studies showed that SP-D downregulates the inflammatory response mediated via TLR4 after lipopolysaccharide exposure in vitro [60]. Interestingly, it was demonstrated in ferrets and macaques infected with a lethal dose of $\mathrm{H} 5 \mathrm{~N} 1$ that the expression of SP-D mRNA is decreased [62]. A similar effect was observed in experiments with human alveolar type II cells which show a reduced secretion of SP-D after infection with $\mathrm{H} 1 \mathrm{~N} 1$ virus [63]. Therefore it can be hypothesized that due to the decrease of SP-D expression during $\mathrm{H} 5 \mathrm{~N} 1$ infection, TLR4 signaling is not downregulated and may contribute to acute lung injury during IAV infection.

\section{Unique Properties of SP-D from Pigs}

Several studies have shown that pSP-D can inhibit IAV of various subtypes more efficiently than hSP-D [22, 33] and that pSP-D can bind hSP-D-resistant strains that belong to the H5N1 subtype and pandemic 2009 H1N1 subtype although inefficiently [22, 43]. These species-specific differences in anti-IAV activity can be explained by the presence of unique structural properties in the CRD of pSP-D which are absent in SP-Ds from other animal species characterized to date [64]. Firstly, the CRD of pSP-D contains an N-linked, complex oligosaccharide at Asn303 that is fully sialylated with $\alpha(2,6)$-linked SAs [65]. It was shown that the presence of terminal SAs on this complex glycan in the CRD contributes to the hemagglutinationinhibitory capacity of pSP-D against IAV $[33,66]$ (fig. 3b). This interaction appears even more relevant for $\mathrm{pSP}-\mathrm{D}$ mediated neutralization of IAVs that are poorly glycosylated [66]. Secondly, the CRD of pSP-D contains a unique tripeptide loop region that alters the lectin site conformation of the CRD, as described in a recent study on the crystal structure of a neck-CRD fragment of pSP-D [67]. Modeling studies suggest that this GSS-loop region facilitates interactions with distal portions of branched mannoside and results in distinct, high-affinity interactions between pSP-D and mannose-rich oligosaccharides expressed on the IAV surface.

Of interest, although pigs can be infected by IAV, the mortality rate is low $(<1 \%)$ and they may be partially protected against infection by pSP-D [68]. The 2009 pandemic $\mathrm{H} 1 \mathrm{~N} 1$ viruses are of swine origin and are poorly glycosylated, making them fully resistant to neutralization by human SP-D [43] and less sensitive to inhibition by pSP-D [49]. This could favor escape from recognition by SP-D. Furthermore, commercial pigs have a limited life span which limits the selective pressure mediated by antibodies compared to humans [17, $69,70]$. It could be hypothesized that components of the innate immune system are more important for selective pressure than the adaptive immune system and antibodies in particular. Of interest, antigenic evolution is associated with a gain of $\mathrm{N}$-linked glycosylation sites [71, 72] and therefore pandemic influenza viruses such as 2009 pandemic H1N1 may become more susceptible to the action of SP-D, which may contribute to restricted tropism to the upper respiratory tract, comparable to seasonal IAV of the H3N2 subtype and prepandemic $\mathrm{H} 1 \mathrm{~N} 1$ viruses [73].

\section{Role of SP-D against IAV in vivo}

SP-D knockout mice have been generated for more than 10 years ago. Mice heterozygous for the SP-D gene produce $50 \%$ less SP-D but display a normal phenotype. SP-D-deficient mice show a progressive accumulation of surfactant lipids and SP-A and SP-B in the alveolar space, the alveolar phospholipid pool being 8 times higher compared to the wild-type mice. There is also an accumulation of macrophages and alveolar type II cells are hyperplastic and contain giant lamellar bodies [74]. This sug- 
gests that SP-D is important for surfactant homeostasis in the lungs. The phenotype of SP-D null mice can be reversed by administration of recombinant SP-D to their lungs. Of note, a mutant lacking the collagen domain of SP-D failed to reverse the phenotype [75], indicating that multimerization of SP-D is required to restore lung homeostasis.

After infection of wild-type mice with highly glycosylated IAV, endogenous SP-D increases while SP-D-deficient mice show a decreased viral clearance that can be reversed if RhSP-D is administered to the SP-D-deficient mice. However, during infection with a poorly glycosylated IAV that was resistant to inhibition by SP-D no difference was observed between wild-type and the SP-D knockout mice [76]. This result illustrates that SP-D-mediated clearance of IAV is affected by the degree of viral glycosylation of a particular strain.

\section{Perspectives for SP-D as a Novel Antiviral Drug}

To treat infected individuals, two classes of licensed antiviral drugs against influenza exist. The first are the adamantanes (amantadine and rimantadine), which inhibit the proton channel function of the matrix 2 (M2) protein. The other class of antiviral drugs comprises the NA inhibitors, zanamivir and oseltamivir. Unfortunately, the use of these antiviral drugs has some drawbacks such as side effects but also the emergence of resistant strains. For example, seasonal H3N2 IAV resistant to amantadine emerged in 2000 in Asia and has been the predominant strain ever since [77]. In addition, most of the seasonal $\mathrm{H} 1 \mathrm{~N} 1$ viruses isolated in the influenza season 2008-2009 were resistant to oseltamivir [77-79]. Clearly there is a need for novel classes of antiviral drugs that can be used to treat IAV infections and that do not suffer from these disadvantages.

The use of SP-D as an antiviral drug would offer several advantages. SP-D and especially pSP-D neutralize a broad range of IAVs and, in contrast to the use of NA inhibitors, it is unlikely that a single mutation in the genome of IAV would induce resistance against the antiviral activity of SP-D. Furthermore, SP-D can be administered into the airways to provide acute protection against invading IAV particles. Since SP-D is a naturally occurring substance in the airways, little toxic effects are anticipated and a relatively high immunogenic tolerance for such a biotherapeutic drug in humans. So far, only a few studies have addressed the role of SP-D as a potential antiviral drug. Mice that received a recombinant trimeric
neck-CRD fragment of hSP-D before or repeated doses for several days after inoculation with respiratory syncytial virus displayed lower viral loads compared to untreated mice [80]. As for IAV, a recent study with a similarly truncated hSP-D molecule that also had two mutations engineered into its CRD (D325A/R343V) showed decreased morbidity and enhanced viral clearance in an infection model using mice in contrast to using oligomeric wild-type hSP-D [81]. These first successful anti-IAV studies in vivo can be considered as a major step forward in using SP-D as an antiviral drug against IAV. However, these studies involved coadministration of the modified SP-D after preincubation with IAV followed by application of the SP-D/IAV mixture to the animals. The potency of SP-D as an effective prophylactic or therapeutic drug requires further investigation.

\section{Conclusions}

SP-D shows strong antiviral properties against IAV in vitro and recent in vivo data have indicated that derivatives of this innate immune protein show potential to become a novel, antiviral drug. Of special interest, wild-type pSP-D exhibits strong antiviral properties against a much broader range of IAV strains/subtypes compared to hSP$\mathrm{D}$ as it is naturally expressed in the airways. Future studies that are aimed to improve the antiviral activity of an hSP-D-based antiviral drug will benefit from our expanding knowledge on structure and properties of pSP-D.

\section{Acknowledgement}

This work was supported by grant 10388 from the Technology Foundation STW (Stichting Technische Wetenschappen).

References

J Innate Immun 2013;5:197-208
Gonzalez S, Gonzalez-Rodriguez AP, SuarezAlvarez B, Lopez-Soto A, Huergo-Zapico L, Lopez-Larrea C: Conceptual aspects of self and nonself discrimination. Self Nonself 2011;2:19-25.

2 Voorhout WF, Veenendaal T, Kuroki Y, Ogasawara Y, van Golde LMG, Geuze HJ: Immunocytochemical localization of surfactant protein D (SP-D) in type II cells, Clara cells, and alveolar macrophages of rat lung. J Histochem Cytochem 1992;40:1589-1597.

3 Madsen J, Kliem A, Tornoe I, Skjodt K, Koch C, Holmskov U: Localization of lung surfactant protein $\mathrm{D}$ on mucosal surfaces in human tissues. J Immunol 2000;164:5866-5870. 
4 Bourbon JR, Chailley-Heu B: Surfactant proteins in the digestive tract, mesentery, and other organs: evolutionary significance. Comp Biochem Physiol A Mol Integr Physiol 2001;129:151-161.

5 Herias MV, Hogenkamp A, van Asten AJ, Tersteeg MH, van Eijk M, Haagsman HP: Expression sites of the collectin SP-D suggest its importance in first line host defence: power of combining in situ hybridisation, RT-PCR and immunohistochemistry. Mol Immunol 2007; 44:3324-3332.

6 Hartshorn KL: Role of surfactant protein A and D (SP-A and SP-D) in human antiviral host defense. Front Biosci (Schol Ed) 2010;2: 527-546.

7 World Health Organization: Influenza (Seasonal); Fact Sheet No. 211. WHO, Geneva, 2009.

8 Wiley DC, Skehel JJ: The structure and function of the hemagglutinin membrane glycoprotein of influenza virus. Annu Rev Biochem 1987;56:365-394.

9 Wilson IA, Cox NJ: Structural basis of immune recognition of influenza virus hemagglutinin. Annu Rev Immunol 1990;8:737771.

10 Skehel JJ, Wiley DC: Receptor binding and membrane fusion in virus entry: the influenza hemagglutinin. Annu Rev Biochem 2000;69: 531-569.

11 Rogers GN, D’Souza BL: Receptor binding properties of human and animal $\mathrm{H} 1$ influenza virus isolates. Virology 1989;173:317-322.

$\checkmark 12$ Thompson CI, Barclay WS, Zambon MC, Pickles RJ: Infection of human airway epithelium by human and avian strains of influenza a virus. J Virol 2006;80:8060-8068.

13 van Riel D, Munster VJ, de Wit E, Rimmelzwaan GF, Fouchier RA, Osterhaus AD, Kuiken T: Human and avian influenza viruses target different cells in the lower respiratory tract of humans and other mammals. Am J Pathol 2007;171:1215-1223.

14 Matrosovich MN, Gambaryan AS, Teneberg S, Piskarev VE, Yamnikova SS, Lvov DK, Robertson JS, Karlsson KA: Avian influenza A viruses differ from human viruses by recognition of sialyloligosaccharides and gangliosides and by a higher conservation of the HA receptor-binding site. Virology 1997;233: 224-234.

15 Suzuki Y: Sialobiology of influenza: molecular mechanism of host range variation of influenza viruses. Biol Pharm Bull 2005;28:399408.

16 Shinya K, Ebina M, Yamada S, Ono M, Kasai N, Kawaoka Y: Avian flu: influenza virus receptors in the human airway. Nature 2006; 440:435-436.

17 Smith DJ, Lapedes AS, de Jong JC, Bestebroer $\mathrm{TM}$, Rimmelzwaan GF, Osterhaus AD, Fouchier RA: Mapping the antigenic and genetic evolution of influenza virus. Science 2004;305:371-376
Girard MP, Tam JS, Assossou OM, Kieny MP: The 2009 A (H1N1) influenza virus pandemic: a review. Vaccine 2010;28:4895-4902.

19 Crouch EC, Persson A, Chang D, Heuser J: Molecular structure of pulmonary surfactant protein D (SP-D). J Biol Chem 1994;269: 17311-17319.

20 Hartshorn KL, White MR, Voelker DR, Coburn J, Zaner K, Crouch EC: Mechanism of binding of surfactant protein $\mathrm{D}$ to influenza $\mathrm{A}$ viruses: importance of binding to haemagglutinin to antiviral activity. Biochem J 2000;351: 449-458.

21 Tecle T, White MR, Crouch EC, Hartshorn KL: Inhibition of influenza viral neuraminidase activity by collectins. Arch Virol 2007; 152:1731-1742.

22 Hillaire ML, van Eijk M, van Trierum SE, van Riel D, Saelens X, Romijn RA, Hemrika W, Fouchier RA, Kuiken T, Osterhaus AD, Haagsman HP, Rimmelzwaan GF: Assessment of the antiviral properties of recombinant porcine SP-D against various influenza A viruses in vitro. PLoS One 2011;6:e25005.

23 Brown-Augsburger P, Hartshorn KL, Chang D, Rust K, Fliszar C, Welgus HG, Crouch EC: Site-directed mutagenesis of Cys-15 and Cys20 of pulmonary surfactant protein D. Expression of a trimeric protein with altered anti-viral properties. J Biol Chem 1996;271: 13724-13730.

24 Hartshorn KL, White MR, Tecle T, Tornoe I, Sorensen GL, Crouch EC, Holmskov U: Reduced influenza viral neutralizing activity of natural human trimers of surfactant protein D. Respir Res 2007;8:9.

25 Tecle T, White MR, Sorensen G, Gantz D, Kacak N, Holmskov U, Smith K, Crouch EC, Hartshorn KL: Critical role for cross-linking of trimeric lectin domains of surfactant protein $\mathrm{D}$ in antiviral activity against influenza $\mathrm{A}$ virus. Biochem J 2008;412:323-329.

26 Hartshorn KL, White MR, Tecle T, Sorensen G, Holmskov U, Crouch EC: Viral aggregating and opsonizing activity in collectin trimers. Am J Physiol Lung Cell Mol Physiol 2010;298:L79-L88.

-27 Hartshorn KL, Crouch EC, White MR, Eggleton P, Tauber AI, Chang D, Sastry K: Evidence for a protective role of pulmonary surfactant protein D (SP-D) against influenza A viruses. J Clin Invest 1994;94:311-319.

28 Hartshorn KL, White MR, Shepherd V, Reid KBM, Jensenius JC, Crouch EC: Mechanisms of anti-influenza activity of surfactant proteins A and D: comparison with serum collectins. Am J Physiol 1997;273:L1156-L1166.

29 White MR, Crouch E, Chang D, Hartshorn KL: Increased antiviral and opsonic activity of a highly multimerized collectin chimera. Biochem Biophys Res Commun 2001;286:206213.

30 Rust K, Grosso L, Zhang V, Chang D, Persson A, Longmore WJ, Cai GZ, Crouch EC: $\mathrm{Hu}$ man surfactant protein D: SP-D contains a Ctype lectin carbohydrate recognition domain. Arch Biochem Biophys 1991;290:116-126.
Crouch EC, Smith K, McDonald B, Briner D, Linders B, McDonald J, Holmskov U, Head J, Hartshorn K: Species differences in the carbohydrate binding preferences of surfactant protein D. Am J Respir Cell Mol Biol 2006;35: 84-94.

- 32 Crouch E, Hartshorn K, Horlacher T, McDonald B, Smith K, Cafarella T, Seaton B, Seeberger $\mathrm{PH}$, Head J: Recognition of mannosylated ligands and influenza A virus by human surfactant protein $\mathrm{D}$ : contributions of an extended site and residue 343 . Biochemistry 2009;48:3335-3345.

33 van Eijk M, White MR, Crouch EC, Batenburg JJ, Vaandrager AB, van Golde LMG, Haagsman HP, Hartshorn KL: Porcine pulmonary collectins show distinct interactions with influenza A viruses; role of the $\mathrm{N}$-linked oligosaccharides in the carbohydrate recognition domain. J Immunol 2003;171:14311440.

- 34 Soerensen CM, Nielsen OL, Willis A Heegaard PM, Holmskov U: Purification, characterization and immunolocalization of porcine surfactant protein D. Immunology 2005;114:72-82.

35 Wilson IA, Skehel JJ, Wiley DC: Structure of the haemagglutinin membrane glycoprotein of influenza virus at 3 A resolution. Nature 1981;289:366-373.

-36 Reading PC, Morey LS, Crouch EC, Anders EM: Collectin-mediated antiviral host defense of the lung: evidence from influenza virus infection of mice. J Virol 1997;71:82048212.

37 Das SR, Hensley SE, David A, Schmidt L, Gibbs JS, Puigbo P, Ince WL, Bennink JR, Yewdell JW: Fitness costs limit influenza A virus hemagglutinin glycosylation as an immune evasion strategy. Proc Natl Acad Sci USA 2011;108:E1417-E1422.

38 Reading PC, Miller JL, Anders EM: Involvement of the mannose receptor in infection of macrophages by influenza virus. J Virol 2000; 74:5190-5197.

39 Reading PC, Pickett DL, Tate MD, Whitney PG, Job ER, Brooks AG: Loss of a single Nlinked glycan from the hemagglutinin of influenza virus is associated with resistance to collectins and increased virulence in mice. Respir Res 2009;10:117.

-40 Tate MD, Job ER, Brooks AG, Reading PC: Glycosylation of the hemagglutinin modulates the sensitivity of H3N2 influenza viruses to innate proteins in airway secretions and virulence in mice. Virology 2011;413: 84-92.

41 Tate MD, Brooks AG, Reading PC: Specific sites of N-linked glycosylation on the hemagglutinin of H1N1 subtype influenza A virus determine sensitivity to inhibitors of the innate immune system and virulence in mice. J Immunol 2011;187:1884-1894.

Hillaire/Haagsman/Osterhaus/ Rimmelzwaan/van Eijk 
-42 Qi L, Kash JC, Dugan VG, Jagger BW, Lau YF, Sheng ZM, Crouch EC, Hartshorn KL, Taubenberger JK: The ability of pandemic influenza virus hemagglutinins to induce lower respiratory pathology is associated with decreased surfactant protein D binding. Virology 2011;412:426-434.

- 43 Job ER, Deng YM, Tate MD, Bottazzi B, Crouch EC, Dean MM, Mantovani A, Brooks AG, Reading PC: Pandemic H1N1 influenza A viruses are resistant to the antiviral activities of innate immune proteins of the collectin and pentraxin superfamilies. J Immunol 2010; 185:4284-4291.

-44 Vigerust DJ, Ulett KB, Boyd KL, Madsen J, Hawgood S, McCullers JA: N-linked glycosylation attenuates $\mathrm{H} 3 \mathrm{~N} 2$ influenza viruses. J Virol 2007;81:8593-8600.

-45 Hawgood S, Brown C, Edmondson J, Stumbaugh A, Allen L, Goerke J, Clark H, Poulain F: Pulmonary collectins modulate strain-specific influenza a virus infection and host responses. J Virol 2004;78:8565-8572.

46 Hartshorn KL, Webby R, White MR, Tecle T, Pan C, Boucher S, Moreland RJ, Crouch EC, Scheule RK: Role of viral hemagglutinin glycosylation in anti-influenza activities of recombinant surfactant protein D. Respir Res 2008;9:65.

47 Das SR, Puigbo P, Hensley SE, Hurt DE, Bennink JR, Yewdell JW: Glycosylation focuses sequence variation in the influenza $A$ virus $\mathrm{H} 1$ hemagglutinin globular domain. PLoS Pathog 2010;6:e1001211.

-48 Gamblin SJ, Haire LF, Russell RJ, Stevens DJ, Xiao B, Ha Y, Vasisht N, Steinhauer DA, Daniels RS, Elliot A, Wiley DC, Skehel JJ: The structure and receptor binding properties of the 1918 influenza hemagglutinin. Science 2004;303:1838-1842.

-49 Hillaire ML, van Eijk M, Nieuwkoop NJ, Vogelzang-van Trierum SE, Fouchier RA, Osterhaus AD, Haagsman HP, Rimmelzwaan GF: The number and position of N-linked glycosylation sites in the hemagglutinin determine differential recognition of seasonal and 2009 pandemic H1N1 influenza virus by porcine surfactant protein D. Virus Res 2012;169: 301-305.

50 Cohen J: Swine flu pandemic. What's old is new: 1918 virus matches 2009 H1N1 strain. Science 2010;327:1563-1564.

51 Chen W, Sun S, Li Z: Two glycosylation sites in $\mathrm{H} 5 \mathrm{~N} 1$ influenza virus hemagglutinin that affect binding preference by computer-based analysis. PLoS One 2012;7:e38794.

52 Hartshorn KL, Crouch EC, White MR, Colamussi ML, Kakkanatt A, Tauber B, Shepherd V, Sastry KN: Pulmonary surfactant proteins $A$ and D enhance neutrophil uptake of bacteria. Am J Physiol 1998;274:L958-L969.

-53 Cai GZ, Griffin GL, Senior RM, Longmore WJ, Moxley MA: Recombinant SP-D carbohydrate recognition domain is a chemoattractant for human neutrophils. Am J Physiol 1999;276:L131-L136.
Fournier B, Andargachew R, Robin AZ, Laur O, Voelker DR, Lee WY, Weber D, Parkos CA: Surfactant protein D (Sp-D) binds to membrane-proximal domain (D3) of signal regulatory protein alpha (SIRPalpha), a site distant from binding domain of CD47, while also binding to analogous region on signal regulatory protein beta (SIRPbeta). J Biol Chem 2012;287:19386-19398.

55 Hartshorn KL, Reid KBM, White MR, Jensenius JC, Morris SM, Tauber AI, Crouch EC: Neutrophil deactivation by influenza A viruses: mechanisms of protection after viral opsonization with collectins and hemagglutination-inhibiting antibodies. Blood 1996;87: 3450-3461.

56 White MR, Crouch E, Vesona J, Tacken PJ, Batenburg JJ, Leth-Larsen R, Holmskov U, Hartshorn KL: Respiratory innate immune proteins differentially modulate the neutrophil respiratory burst response to influenza A virus. Am J Physiol Lung Cell Mol Physiol 2005;289:L606-L616.

57 White MR, Tecle T, Crouch EC, Hartshorn KL: Impact of neutrophils on antiviral activity of human bronchoalveolar lavage fluid. Am J Physiol Lung Cell Mol Physiol 2007; 293:L1293-L1299.

58 Hartshorn KL, White MR, Tecle T, Holmskov $\mathrm{U}$, Crouch EC: Innate defense against influenza A virus: activity of human neutrophil defensins and interactions of defensins with surfactant protein D. J Immunol 2006;176:69626972.

59 Ohya M, Nishitani C, Sano H, Yamada C, Mitsuzawa H, Shimizu T, Saito T, Smith K, Crouch E, Kuroki Y: Human pulmonary surfactant protein D binds the extracellular domains of Toll-like receptors 2 and 4 through the carbohydrate recognition domain by a mechanism different from its binding to phosphatidylinositol and lipopolysaccharide. Biochemistry 2006;45:8657-8664.

60 Yamazoe M, Nishitani C, Takahashi M, Katoh T, Ariki S, Shimizu T, Mitsuzawa H, Sawada K, Voelker DR, Takahashi H, Kuroki Y: Pulmonary surfactant protein D inhibits lipopolysaccharide (LPS)-induced inflammatory cell responses by altering LPS binding to its receptors. J Biol Chem 2008;283:3587835888.

61 Imai Y, Kuba K, Neely GG, Yaghubian-Malhami R, Perkmann T, van Loo G, Ermolaeva M, Veldhuizen R, Leung YH, Wang H, Liu H, Sun Y, Pasparakis M, Kopf M, Mech C, Bavari S, Peiris JS, Slutsky AS, Akira S, Hultqvist M, Holmdahl R, Nicholls J, Jiang C, Binder CJ, Penninger JM: Identification of oxidative stress and Toll-like receptor 4 signaling as a key pathway of acute lung injury. Cell 2008; 133:235-249.

62 Kongchanagul A, Suptawiwat O, Boonarkart C, Kitphati R, Puthavathana P, Uiprasertkul M, Auewarakul P: Decreased expression of surfactant protein D mRNA in human lungs in fatal cases of H5N1 avian influenza. J Med Virol 2011;83:1410-1417.
63 Wang J, Nikrad MP, Phang T, Gao B, Alford T, Ito Y, Edeen K, Travanty EA, Kosmider B, Hartshorn K, Mason RJ: Innate immune response to influenza A virus in differentiated human alveolar type II cells. Am J Respir Cell Mol Biol 2011;45:582-591.

-64 van Eijk M, Haagsman HP, Skinner T, Archibold A, Reid KBM, Lawson PR: Porcine lung surfactant protein $\mathrm{D}$ : complementary DNA cloning, chromosomal localization, and tissue distribution. J Immunol 2000; 164 : 1442-1450.

65 van Eijk M, van de Lest CHA, Batenburg JJ, Vaandrager AB, Meschi J, Hartshorn KL, van Golde LMG, Haagsman HP: Porcine surfactant protein $\mathrm{D}$ is $\mathrm{N}$-glycosylated in its carbohydrate recognition domain and is assembled into differently charged oligomers. Am J Respir Cell Mol Biol 2002;26:739-747.

66 van Eijk M, White MR, Batenburg JJ, Vaandrager $\mathrm{AB}$, van Golde LM, Haagsman HP, Hartshorn KL: Interactions of influenza A virus with sialic acids present on porcine surfactant protein D. Am J Respir Cell Mol Biol 2004;30:871-879.

67 van Eijk M, Rynkiewicz MJ, White MR, Hartshorn KL, Zou X, Schulten K, Luo D, Crouch EC, Cafarella TR, Head JF, Haagsman HP, Seaton BA: A unique sugar-binding site mediates the distinct anti-influenza activity of pig surfactant protein D. J Biol Chem 2012; 287:26666-26677.

$68 \mathrm{Ma}$ W, Lager KM, Vincent AL, Janke BH, Gramer MR, Richt JA: The role of swine in the generation of novel influenza viruses. Zoonoses Public Health 2009;56:326-337.

69 de Jong JC, Palache AM, Beyer WE, Rimmelzwaan GF, Boon AC, Osterhaus AD: Haemagglutination-inhibiting antibody to influenza virus. Dev Biol (Basel) 2003;115:63-73.

70 de Jong JC, Smith DJ, Lapedes AS, Donatelli I, Campitelli L, Barigazzi G, Van Reeth K, Jones TC, Rimmelzwaan GF, Osterhaus AD, Fouchier RA: Antigenic and genetic evolution of swine influenza A (H3N2) viruses in $\mathrm{Eu}-$ rope. J Virol 2007;81:4315-4322.

71 Zhang M, Gaschen B, Blay W, Foley B, Haigwood N, Kuiken C, Korber B: Tracking global patterns of $\mathrm{N}$-linked glycosylation site variation in highly variable viral glycoproteins: HIV, SIV, and HCV envelopes and influenza hemagglutinin. Glycobiology 2004;14:12291246.

72 Igarashi M, Ito K, Kida H, Takada A: Genetically destined potentials for N-linked glycosylation of influenza virus hemagglutinin. Virology 2008;376:323-329.

73 van Riel D, den Bakker MA, Leijten LM, Chutinimitkul S, Munster VJ, de Wit E, Rimmelzwaan GF, Fouchier RA, Osterhaus AD, Kuiken T: Seasonal and pandemic human influenza viruses attach better to human upper respiratory tract epithelium than avian influenza viruses. Am J Pathol 2010;176:16141618. 
74 Botas C, Poulain F, Akiyama J, Brown C, Allen L, Goerke J, Clements JA, Carlson E, Gillespie AM, Epstein C, Hawgood S: Altered surfactant homeostasis and alveolar type II cell morphology in mice lacking surfactant protein D. Proc Natl Acad Sci USA 1998;95: 11869-11874.

75 Zhang L, Hartshorn KL, Crouch EC, Ikegami $\mathrm{M}$, Whitsett JA: Complementation of pulmonary abnormalities in SP-D (-/-) mice with a $\mathrm{SP}-\mathrm{D} /$ conglutinin fusion protein. J Biol Chem 2002;277:22453-22459.

76 LeVine AM, Whitsett JA, Hartshorn KL, Crouch EC, Korfhagen TR: Surfactant protein $\mathrm{D}$ enhances clearance of influenza A virus from the lung in vivo. J Immunol 2001;167: 5868-5873.
7 Bright RA, Medina MJ, Xu X, Perez-Oronoz G, Wallis TR, Davis XM, Povinelli L, Cox NJ, Klimov AI: Incidence of adamantane resistance among influenza A ( $\mathrm{H} 3 \mathrm{~N} 2)$ viruses isolated worldwide from 1994 to 2005: a cause for concern. Lancet 2005;366:1175-1181.

78 Deyde VM, Xu X, Bright RA, Shaw M, Smith $\mathrm{CB}$, Zhang Y, Shu Y, Gubareva LV, Cox NJ, Klimov AI: Surveillance of resistance to adamantanes among influenza $\mathrm{A}(\mathrm{H} 3 \mathrm{~N} 2)$ and $\mathrm{A}(\mathrm{H} 1 \mathrm{~N} 1)$ viruses isolated worldwide. J Infect Dis 2007;196:249-257.

79 World Health Organization: Influenza A (H1N1) Virus Resistance to Oseltamivir 2008/2009 Influenza Season, Northern Hemisphere. Geneva, WHO, 2011.

80 Hickling TP, Bright $\mathrm{H}$, Wing K, Gower D, Martin SL, Sim RB, Malhotra R: A recombinant trimeric surfactant protein $\mathrm{D}$ carbohydrate recognition domain inhibits respiratory syncytial virus infection in vitro and in vivo. Eur J Immunol 1999;29:3478-3484.
81 Crouch E, Nikolaidis N, McCormack FX, McDonald B, Allen K, Rynkiewicz MJ, Cafarella TM, White M, Lewnard K, Leymarie N, Zaia J, Seaton BA, Hartshorn KL: Mutagenesis of surfactant protein $\mathrm{D}$ informed by evolution and $\mathrm{x}$-ray crystallography enhances defenses against influenza $\mathrm{A}$ virus in vivo. J Biol Chem 2011;286:40681-40692.

82 Veldhuizen EJ, van Eijk M, Haagsman HP: The carbohydrate recognition domain of collectins. FEBS J 2011;278:3930-3941.

83 Xu R, McBride R, Nycholat CM, Paulson JC, Wilson IA: Structural characterization of the hemagglutinin receptor specificity from the 2009 H1N1 influenza pandemic. J Virol 2012; 86:982-990. 